Domination of English and Its Impact on the Arabic System of Scholarly Communication

\begin{tabular}{c}
\hline Ali Saif Al-Aufi \\
\hline Assistant Professor \\
Sultan Qaboos University \\
College of Arts \& Social Sciences \\
Department of Information Studies \\
alaufia@squ.edu.om
\end{tabular}




\title{
Domination of English and its impact on the Arabic System of Scholarly Communication
}

\author{
Ali Saif Al-Aufi
}

\section{Abstract:}

While English, supported by technological development and the advent of networked information, has overwhelmingly played a dominating force in the world-wide system of scholarly communication, it has created a deficiency in local scholarly communication systems; the Arabic scholarly communication system is no exception. This paper investigates the impact of English language on the Arab academics' practices in and attitudes towards research and scholarly communication. It also assesses the challenges facing the future of Arabic scholarship, in particular the crisis regarding the use of the Arabic language in the academic networked environment. A qualitative approach containing semi-structured interviews was utilized to collect rich data about the academics' practices and attitudes on their choice of language for research and scholarly communication and whether the dominant use of English, especially in science disciplines, hinders the potential of Arabic scholarship to contribute in the development of Arabic as a scholarly language.

Key Words: Scholarly communication, Networked Information, linguistic divide, Arabic language, Arab World, Sultan Qaboos University, Oman

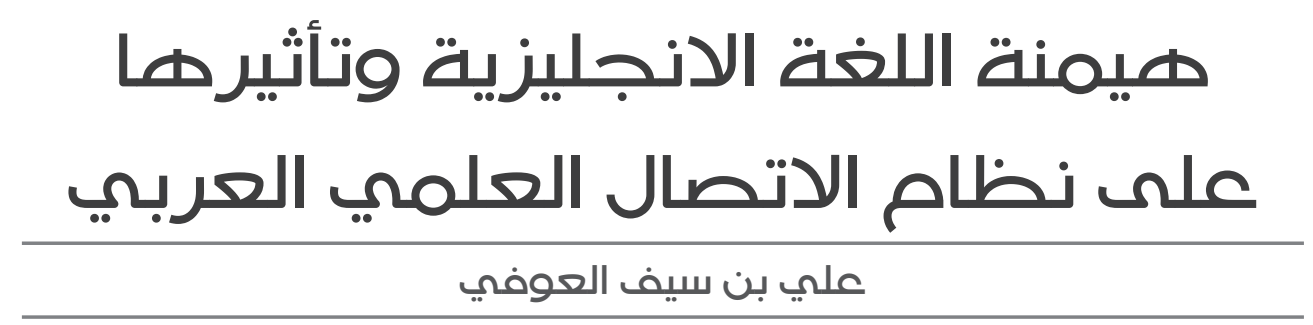

مستخلص: في حين أن اللغة الإنجليزية، مدعومة بواسطة التطورات التقنية وانتشار مصادر المعلومات الرقمية وخدماتها، لعبت بجدارة دارئ دور

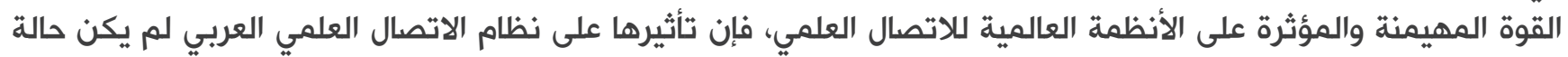

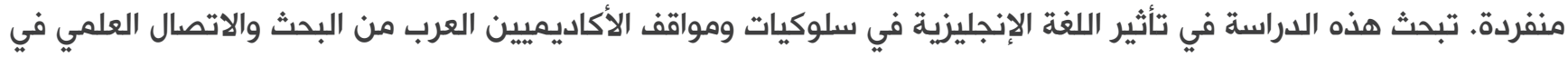

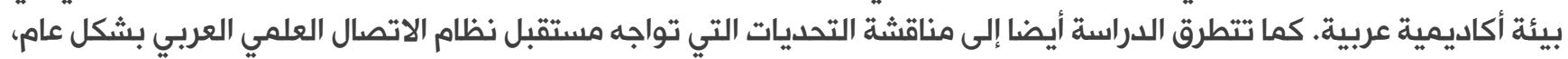

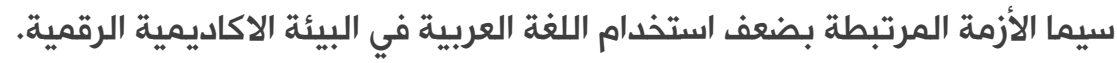

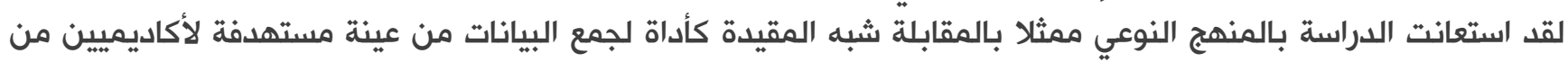

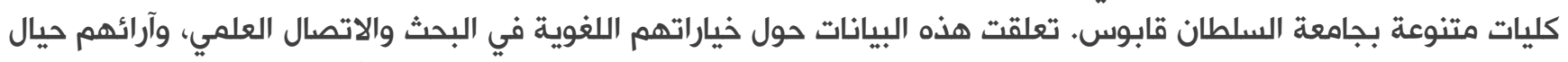

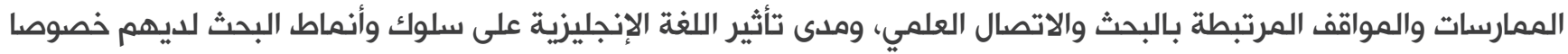

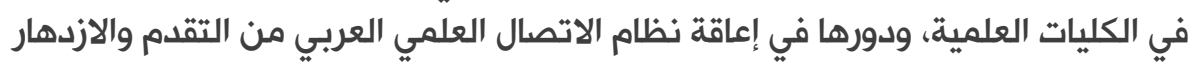

الكلمات الدالة: الاتصال العلمي، المعلومات الرقمية، الفجوة اللغوية، اللغة العربية، العالم العربي، جامعة السلطان قابوس، سلطنة عمان 


\section{Introduction:}

For most computer users, and recently mobile computing users, networking technology was first made available with the advent of the Internet and the associated technology of the World Wide Web. As a result of the Internet, the public gained access to numerous types of networked information resources and services, including e-mail, mailing lists, bulletin boards, Internet chat, social networking applications, and different multimedia formats, both audio and visual.

Academic users were quick to take advantage of these developments and others that were delivered to their desktop or hand-held gadgets as the internet became established as the common delivery platform for digital information services. In particular the rapid implementation and acceptance of 'networked information' in the form of web-based delivery of academic content such as e-journals, library catalogues, and bibliographic databases, transformed the processes of research and scholarly communication in the academic environment. Networked information has fundamentally changed the manner in which academics correspond and work, and has had a far-reaching impact on many aspects of the research environment, including the accessibility of information; collaborative research, and the dissemination of research outputs.

Academic institutions are at the forefront in harvesting the benefits of the Internet and networked information, which have become integral components of contemporary higher education and research environments (Wang \& Cohen, 2000). Academics have generally embraced a paradigm shift in their patterns of use of information research and scholarly communication purposes, and this change has been felt in many aspects of higher education. Academic libraries in particular have been required to transform their collections and services due to the emergence of the Internet and networked information (Kebede, 2002; Tam \& Robertson, 2002), and as a result, the relationships between libraries and their users have been profoundly changed.

The Internet and networked communication have not, however, impacted equally on higher education, universities, and individual academics in all countries. Differences between countries in their rates of technology adoption, social conditions, educational systems, and methods of information exchange, have resulted in differences in the extent to which transformation has occurred. Inevitably the change has been more rapid in those countries which enjoy a more fully implemented technology and communication infrastructure; a more highly developed system of higher education and research, and established networks and standards of scholarly communication. Many of these countries use English as a first language, particularly for the purposes of academic exchange.

The research reported here is an attempt to trace the impact of English language on patterns of research and scholarly communication in an Arabic context and assess the challenges it may pose for the future of the Arabic scholarly communication, using Sultan Qaboos University as an academic setting of one such developing country, Oman. Not all developing countries are equal in this regard. There are for example, substantial differences in the financial capacity, social circumstances and political ambition of 
developing countries in Africa, Asia and the Middle East. The situation in Oman is therefore used as a study relevant to one group of countries-those of the rapidly developing Arab Middle East.

\section{Statement of the Problem}

Research on scholarly communication practices conducted in the developed countries has significantly exceeded the amount of research conducted in developing countries. Studies of academic adoption of the Internet and networked information therefore need to be conducted in developing Arab countries in order to; assess the information and technology gaps that exist between developing Arab countries and developed countries and also between developing Arab countries and other groups of developing countries, identify if patterns of research related uses of networking technologies in developing Arab countries have been influenced by local factors, such as the existing social, educational, and linguistic factors, and assess the impact that networking technologies have had on the research productivity of academics in developing Arab countries.

An important element of the Arab Human Development Report is that it concluded that Arabic is a "language in crisis". The Report identified a number of aspects to this crisis, including the "challenges raised by information technology, which relate to the computerized automation of the language" (United Nations Development Programme, 2003, p.7), and emphasized the central role of language in the maintenance and well-being of any socio-cultural system. In addition the Report called for the "arabicization" of university education in relevant countries, noting that the "failure to arabicize science creates obstacles to communication between scientific disciplines and slows knowledge exchange" (United Nations Development Programme, 2003, p.7). In other words, the current policy of some Arab governments-including Omanof promoting the use of English for teaching and research at the expense of Arabic, is held to be detrimental to not only the productivity and relevance of their academic sector, but also to the long-term development and wellbeing of Arab societies. The challenge set for Arab governments is therefore to develop the policies and infrastructure capable of producing adequate digital content in Arabic. This is held to be important for both preserving and making available the best of existing Arabic scholarship, and for supporting the ongoing research of current and future Arabic-speaking scholars.

Since the Internet was introduced to Sultan Qaboos University (SQU) in late 1997, the use of the Internet by the University's academics for purposes of research and scholarly communication has remained largely unexamined. However SQU, like most of the Arab universities and particularly those in the Gulf States, is characterized by the use of the English language for both teaching and research. As a result, the use of Arabic language has diminished to the extent where it is now the preferred language for teaching and research in a few discrete areas of humanities and social sciences disciplines only. This is a process that is driven not only by government policy, but also by the domination of English of the globalized scholarly communication made available via the Internet and other networked information services. Crucially, there have been no significant attempts to examine Arab scholars' attitudes towards the decline of Arabic for scholarly purposes.

This study, therefore, aims to assess the state 
of the transition in a developing Arab country to the new forms of scholarly communication that are dependent on networked information facilitated extensively by English language. With such issues in mind an important component of the current research is the examination of attitudes of academics at an Arab university to the comparative use of English and Arabic for scholarly purposes.

\section{Research Objectives}

The primary objectives of the proposed study are to:

1. Investigate the impact of English as a scholarly dominating language on the Arab academic patterns and attitudes in research and scholarly communication in an Arabic context, using Sultan Qaboos University as an example.

2. Assess the challenges facing the future of Arabic scholarly communication in the networked environment.

\section{Research Questions}

In meeting these objectives, the study intends to address the following research questions:

1. To what extent has the domination of the English language impacted on the Arabic scholarly communication system?

2. Are there any constraints on the use of Arabic networked information for research and scholarly communication?

3. What are the challenges facing the future of Arabic scholarship?

\section{Literature Review}

Carefully reviewing both English and Arabic literature to find research on the use of English and/or Arabic language in the Arabic networked academic environments revealed no studies that directly deal with this matter. However, some studies were found to be partially relevant and therefore helpful in establishing the larger picture. These studies generally look at the attitudes of using English as opposed to Arabic for educational purposes, and the wider issue of the spread of English within Arabic-speaking societies.

Warschauer, El-Said, \& Zohry (2002) conducted a study, using both questionnaire (43 respondents) and interview (4 participants), to investigate how English and Arabic are used online by a group of young professionals in Egypt. Although the study was not intended to examine the use of English in an academic environment or for the purpose of research and scholarly communication, it helps by revealing attitudes regarding language preference in an Arab community. The result indicates that for e-mail, English was used much more frequently (83\%) for the purpose of formal communication, while, on the other hand, Arabic or a combination of Arabic and English is more favored for the purpose of informal communication. The majority of participants (71\%) reported preferring English for the purpose of online chat. The positive attitudes toward English were reported as being the result of the domination of English in the networked environment; lack of Arabic software and standardization; inappropriateness of teaching and learning computer and Internet technologies by means of Arabic, and good English language skills among youth adopters.

Al-Jurf (2004) conducted a study to investigate the attitudes of university students towards using Arabic or English for learning and instruction. 
She distributed a questionnaire to a sample of students from science disciplines at the University of Jordan and to a sample of students in the College of Languages and Literature at King Saud University in Saudi Arabia. The author also conducted interviews with students' parents. The overall findings of the study indicated positive attitudes toward using English in preference to Arabic for educational purposes. Almost half of the interviewees indicated that they will enrol their children in pure English teaching schools or colleges in the future. Also, the majority of the respondents from the University of Jordan (96\%) and King Saud University (82\%) reported that they no longer consider Arabic to be suitable for teaching science disciplines. Respondents asserted that Arabic might only be useful to teach certain disciplines within the humanities and social sciences. The study also revealed that there is a language divide between English and Arabic in terms of the scientific terminology available in English that has no counterpart in Arabic. The majority of the parents interviewed encourage their children to access educational knowledge by means of English. A range of factors, including scientific, technological, professional, educational, and social, were used to explain this preference for English. Lack of translation and 'Arabization' and lack of research and authoring in Arabic are also major influences that are identified as impacting negatively on the use of Arabic as a medium for teaching and learning.

Findlow (2006) examined the increase in the use of English as a medium of higher education in the Arab World, particularly the Arab Gulf countries. She intended to explore the relationship between higher education, language shift and cultural reproduction in a bilingual educational system.
As part of her research, she conducted interviews (in Arabic when necessary) with 65 students, teachers and educational administrators in higher education institutions in the United Arab Emirates. She also distributed 500 questionnaires in both Arabic and English to university students, of which she chose 340 questionnaires for the purpose of analysis. Findings revealed a positive preference for English over Arabic. When students were asked whether they prefer to be taught in Arabic or English, only 22\% indicated Arabic, while in contrast, 50\% indicated English. The remainder of the participants (28\%) ignored the only given two choices and inserted both Arabic and English. Academics also indicated positive attitudes toward English. They expressed a preference for English because it is the international language, or the language of the world educational market. It would appear from the result of this study that the major determining factor that impacts on students' preference for English is societal. Students feel that learning in English is appropriate, both to helping them get a satisfactory employment outcome and also as a service to the development of their country of origin in a way that would not be achieved if Arabic was the only choice.

In reading the results of the above studies, it can be concluded that the attitudes of native Arabic speakers toward using English is largely determined by the domination of English in the networked environment as it constitutes almost $80 \%$ of the content on the Internet (Warschauer, El-Said, \& Zohry, 2002). By contrast, careful strategic planning and active support by governments will be essential to help the Arabic language play an effective role in transmitting the results of Arab scholarship. 


\section{Methodology}

This study is primarily concerned with investigating the impact of English as a scholarly dominating language on the Arab academics' patterns and attitudes in an Arabic academic environment. The methodology that has been selected is qualitative in nature combining literature analysis and semi-structured interviews. A small purposive sample size was undertaken in order to expand and enrich the qualitative findings. The methods were mutually supportive, in that findings from the relevant literature revealed issues that needed additional investigation in the interviews, and the outcomes from the interviews assisted in interpreting and discussing the overall finding of the literature.

In particular, emphasis was given to the participants' perspectives about Arabic as a scholarly language in the networked academic environment, including the comparative efficacy of English and Arabic languages for scholarly communication. The interview proved to be an effective means of discovering detailed information from the participants about their practices, opinions, and attitudes. A semi-structured interview was used so that all interviewees would be asked the same general set of questions, but also be given the opportunity to guide the discussion and provide opinions and views on related aspects of interest to them as they arose in the course of the interview.

After the interview was designed and the questions were determined, the researcher pre-tested the format with two Arabic speaking academics. Both of these pre-test interviews were tape-recorded. This process of pre-testing the interview allowed the researcher to reflect on the interview questions; determine the average time needed to complete the interview, and also rehearse and conduct the process beforehand. As a result several minor changes to particular questions were made in order to achieve greater clarity. The final number of conducted interviews was thirteen, which included participants from all colleges at SQU

Once the interviewees were identified, they were contacted by phone and/or personal visits to their offices and thanked for their willingness to participate. The researcher also reminded them about the topic of the study and that they had been chosen-based on their self-nominationto participate in the interviews. They were also asked if they would agree to the tape-recording of the interview. All of the potential interviewees contacted in this way responded positively and expressed their willingness to participate further in the study. Appointments were confirmed at least two days before conducting the interview. Interviewees also received by e-mail copies of the interview schedule and additional details about the topic of the study and the process of conducting the interview. This included an estimate of the amount of time required for the interview.

All interviews took place in the interviewees' offices or at some other quiet place that would not be susceptible to disturbance. General conversation and discussion between the researcher and the interviewee was carried out first in order to establish a sense of rapport. This established a friendly atmosphere for the interview and encouraged participants to feel at ease. The researcher re-described the aim of the project and emphasized the expected significance of the findings for enhancing research and scholarly communication at SQU. Prior to commencing the 
formal part of the interview, the interviewees were given the consent form to read and sign.

As mentioned previously, the same questions were asked in sequence to all of the interviewees. However, the semi-structured format enabled some flexibility and allowed for new and relevant issues to be discussed whenever they seemed to be appropriate and important. Such a process improved and enhanced the richness of the interview findings.

The average time taken to complete the interviews was approximately 30 minutes. All of the interviews were conducted face-to-face and all of them were tape-recorded. Of the interviews, ten were conducted in English, while three were conducted in Arabic upon the request of the participants. Although these three interviewees claimed that they speak English to some extent, they found it easier and more comfortable to express their opinions and thoughts in Arabic. At the transcription phase the interviewer translated the Arabic interviews into English.

Tape-recording the interviews allowed the researcher to pay additional close attention to the discussion and to later enrich the analysis of the interviews by drawing upon direct quotations from the transcribed text. The researcher transcribed the tapes and once full transcriptions were completed, the researcher checked the accuracy of the completed transcripts against the tape-recordings. The texts of the interviews were then sent to the interviewees for a final check on the content and the accuracy of the transcription. Interviewees were also asked if they had further comments that they wished to make on the subject of the interviews. Of the interviewees, nine replied while four did not. Of those who replied, one interviewee requested minor changes to some details about the area of his research, and all others found that the transcripts were accurate and they had no wish for amendments.

The qualitative data resulting from the interviews required the imposition of a conceptual framework which necessitated coding, generating themes, weighting, contrasting, comparing data, and interpreting the data. After full transcripts of the interviews were prepared, the investigator examined these transcripts to identify and elaborate concepts and themes, and then coded the interview data according to these themes. Additional themes were also derived from the literature review and the research objectives and questions. The process of labeling or coding the interview data based on the categorized themes was undertaken manually on separate sheets, in which labels or codes were placed next to each data unit matching a particular theme. These were then typed and organized using Microsoft Word. This process of coding allowed the researcher to quickly locate relevant excerpts and direct quotes from the interview transcripts.

\section{Findings}

The interviews investigated the impact of networked scholarly communication on the use or non-use of Arabic for the purpose of undertaking and publishing research. The interview explored the extent to which Arab academics are concerned about the future use of Arabic for the purpose of scholarly communication. It also investigated the extent to which the domination of English in the networked environment has negatively affected the use of Arabic for research and scholarly communication, and the extent to which Arab universities and their libraries could 
enhance and encourage the use of Arabic in the networked information environment.

\section{English Domination and impact}

Participants were asked to reflect on the extent to which English has dominated networked information and even come to substitute for Arabic networked information for research and scholarly communication purposes. Generally, the interview results in this regard demonstrated that the participants are motivated to value English as a "must" for scholarly purposes, and that they understand that they function in a communication environment which privileges and rewards the use of English. English is considered by participants to be the most important language for effective and professional use by scholars and for users of the Internet more generally.

Participants indicated that the majority of scholarly publishing is in English. They were very conscious that English is the dominant language for scholarly communication, and that the domination of English is similarly evident in both scholarly and general forums on the Internet. In this way English has become the dominant language for both formal and informal scholarly communication.

English is very important because most of the resources and references are in English (2: 3-77).

Most of the information available in the Internet is in English (7: 4-15).

Most of the scholarly work on the Internet is in English (9: 3- 13).

I believe that the majority of information in my discipline is available in English (9: 3-16).
Participants also stressed that the use of English is critically important for the use of computers and Internet technologies, noting that lack of English proficiency is a major barrier to productive use of networked information and associated technologies. This is partly due to the current situation whereby much of the software used for the delivery of networked information in the Arab World is still not "Arabized".

If your English is not good, you will have a hard time adapting with these technologies (1:3-18)

English language and IT in general are very important to help you use networked information in an efficient way . . . I can not imagine at all how a person who does not know any English at all can cope with this technology (4: 4-6).

Use of networked information requires two primary skills, which are knowing English and how to deal with computers and its technology (7: 4-77).

A number of participants thereby expressed the belief that English has become indispensable to the transfer and reproduction of knowledge in the Arab World, and is the major language for the carriage of scholarly communication in the Arab World.

It makes it easy for you to find resources if you know English . . . English is an international language (2: 3-77)

If I do not know English, I would not be able to communicate in the academic 
environment (6: 3-10).

Any researcher or academic who lacks English will not be able to achieve well in his/her academic research (7: 4-15).

Interviewees consider English to be critical for research and scholarly communication in the Arab World in that English has become, as the result of its domination of traditional scholarly publishing and more recently the global networks, a de facto universal scholarly language by which research-related information and publishing is made internationally accessible. Participants also noted that producing knowledge in English is far from exclusive to the English speaking countries, with non-English speaking countries having become considerable producers of knowledge in English.

The good thing about English is that it is universal. So, you are not limited to access information in English from English speaking countries, but also from nonEnglish speaking countries including Arabic countries (8: 3-22).

English language is important to be able to globalize your research (12: 3-17).

\section{Role of translation (Arabicization)}

Another issue the interview addressed was the ways in which academics at SQU can commence a partnership with the University's libraries and information centers to help increase the accessibility of networked information, particularly access to Arabic content to support the research and scholarly communication of the Arabic teaching colleges. This was important to determine whether there are potential developments that might improve the services provided by libraries in supporting the delivery of networked information in Arabic, which could in turn increase the amount of information in Arabic on the network and thereby reduce the dependence on English.

The need for additional translation was expressed by a number of interviewees as being an important factor necessary to increasing and supporting the amount and quality of networked information in Arabic on both the Internet and the SQU Intranet. Some participants suggested that the libraries should be responsible for the work of translation through the creation of specialized translation units. However, it is more widely believed that translating scholarly resources is a task for independent organizations, but that academic libraries can assist by collaborating with these organizations to determine the most valuable resources in need of translation.

The following interviewee, for example, considered translation to be very important because a substantial number of academics in the Arabic teaching colleges are unable to use English for their teaching and researching. Therefore, it is seen as important to have translations available in order to increase the amount of information available in Arabic.

The best role the library can play is to translate most of the important resources of information and put them online. Arabic here [at an Arabic teaching college] is very important. As far as I know, about $40 \%$ of academics in the Arabic teaching colleges and maybe more do not know English (6: 4-5).

Translating the most important resources in 
specific disciplines in collaboration with regional universities was suggested as a possible solution to the problem.

Translation is also important, especially to translate the most important information in a specific field. This could be done in collaboration with different universities and libraries in the Arab World (8: 4-20).

As was often the case interviewees were keen to point out when their situation compared unfavorably to that of other countries.

Emphasis should be given to translation. Let us take Japan, for example, they give much attention to translation (12: 4-4).

Another suggestion recommended translating into Arabic the abstracts of articles that are published originally in English. It is considered to be a minimum response in situations where translation of the full article is not possible.

At least, I suggest that the library can translate into Arabic the abstracts of the articles published in the international journals by means of English language. Also, the library should provide an Arabic abstract for the articles and research published at Sultan Qaboos University and provide them on the library website (7: 5-7 1).

The Arab countries currently work separately and without agreed standards on the translation work that is done, which often results in the use of different terminology or non-standard Arabic. This lack of an agreed unified scholarly terminology might also result in problems when designing information retrieval systems. Some participants indicated such problems and called for increased collaboration.

Right now, you find that the translation is not unified. You find a lot of counterparts for certain words in Arabic. For example, the word "mobile phone" has many different names in Arabic which are simply not standardized to one word. Therefore . . , we have to start with unifying the Arabic terms to come up with a standardized language in the Internet ( $1: 4-8)$.

One more thing is the translation which is not standardized especially when translating English words into Arabic. For example, the term 'corrosion', you find at least three acceptable terms in Arabic for the same word. So, we face difficulty in deciding which term is more suitable scientifically (1: 4-26).

\section{Digitization}

Translation from English into Arabic is viewed as being only part of the solution. Interviewees also noted the need for Arabic language journals to be digitized and made widely available.

One more thing the library can do is to adopt the Arabic academic journals related to humanities and social sciences disciplines and make them available on the Internet for free (7: 5-17).

Also, they should put the journals of Sultan Qaboos University in the library website (9: 4-5).

"They can also digitize the important resources of information that are of benefit 
to the Arabic teaching colleges (9: 4-6)

It is [also] important to pay attention to the digitization and start transferring the Arabic heritage, culture, and scientific knowledge to digital forms (13: 4-23).

The need for access to teaching or research material in Arabic is not, however, felt equally across all disciplines. Respondents from the English teaching colleges did not generally observe a need to have networked information available in Arabic language in their disciplines. The reason is very likely that these respondents exclusively depend on English for their research and teaching. Therefore, they indicated that while Arabic would be helpful for academics in the Arabic teaching colleges, it is not necessary for academics in those colleges teaching in English.

Using Arabic language in the scientific colleges is impossible unless you have everything available for the user in Arabic (5: 5-76).

I have not gone through an Arabic article in my field since I started my academic career . . . There are no Arabic journals on the Internet (10: 4-13).

In science disciplines, to be honest, I do not see that there is a need to have Arabic language (3: 4-21).

\section{Disciplinary differences}

The domination of English as the preferred language for international scholarly publishing has substantially impacted on the attitudes of the academics at SQU in conducting and disseminating their research. The interviews reveal a marked preference for English over Arabic for the purpose of research and scholarly communication. The preference for writing and publishing in English has not just affected science disciplines, but the interviews also indicate that some scholars from the humanities and social disciplines also prefer to use English for communicating their research outcomes. The interviews investigated this issue in order to understand more fully the precise reasons why Arab academics prefer to write and publish their research outcomes in English.

All of the participants indicated that writing and publishing in English is more personally advantageous than writing and publishing in Arabic. The interviewees indicated a variety of factors that drive themselves and other Arab academics to write and publish in English.

Some science-based participants indicated that in their discipline Arabic scholarly journals are either not available at all, or available in a very small number only. Science disciplines in most of the Arab academic institutions are now taught in English, and as academics are writing in English this will have a detrimental impact on the amount of material written in Arabic and therefore decrease the demand for those few Arabic journals that are published. These few journals therefore face great difficulty in acquiring the quality of research-related material that might attract a large readership, and therefore in remaining viable.

I am not aware about any Arabic journal in my discipline if there are some (1:4-20)

We do not have Arabic journals, even those published by Sultan Qaboos University, are 
published in English. To be honest, I do not see a journal or a medium published in Arabic if I wanted to write and publish in Arabic (3: 5-10).

I believe that the most important reason is the lack of Arabic journals in science disciplines in particular. Most of the journals available are in English (9: 4-20).

Interviewees also indicated that Arabic journals, if available, have an inferior quality or reputation. This opinion is applied to all disciplines whether they are sciences or humanities and social sciences. It seems that academics have little respect for Arabic journals due to their perceived inferior quality and limited distribution.

Arabic journals have bad reputation and can not be as valuable as the international journals published by means of English (1: 4-24)

Moreover, most of the specialized journals in the Arab World are not good in quality (7: 6-7).

Peer reviewed Arabic journals are very limited and considered of lower quality (8: 5-6).

Moreover, some participants also noted that the process of publishing in Arabic journals is still very traditional. Arabic publishing, as regionally perceived, suffers from the lack of advanced publishing systems; weakness in bibliographic control as evidenced by a lack of indexing and abstracting services, and absence of unified standards for editing and production. One participant verified:
Most of the Arabic journals impose very traditional conditions for publication and do not allow flexibility in documentation and researching (7: 6-14).

Participants also indicated that publishing in Arabic is detrimental to the author's chance for winning a job or achieving promotion. Although this is not made evident in the SQU policies for staffing and promotion, the academic interviewees strongly believe it to be the case.

They get more chances to have a job. I give you an example of a scholar that I know who publishes mostly in French. He found it difficult to be accepted to work in an institution that mainly teaches in English and this is because of his publications (1 1: 4-6).

If there are some Arabic journals, I can not publish in them, because that will affect my promotion as they will not be counted for my promotion (1: 4-22).

The university might not count it for promotion, so, why do I need to spend time and effort to write in Arabic which will not be recognized by the University for promotion (4: 5-75).

Unfortunately, I can say that even in promotion, the weight of English publications is higher and more valued by the University (6: 4-78).

I will tell you the truth that most of the academics in humanities and social sciences disciplines prefer to write and 
publish in English for the purpose of promotion more than for the purpose of reputation (7: 6-5).

For the interview participants, the use of English for scholarly publishing means more readers, more citation, and more recognition. The chance of having one's research papers read and cited adds considerably to the prospects for international peer recognition in a way that that is almost impossible to achieve if publishing in Arabic.

I agree with you that this impacts negatively on Arabic, but you still need to write in English because you will find a lot who can read for you and cite your papers (2: 4-18).

If you look at the publicity of your work, Arabic journals are very limited. So, there is no chance or the chance is very low that you become known if you publish in Arabic (5: 6-78).

Also, to get more international recognition in your field and more readers to read for you is to publish in English (6: 4-19).

The recognition of the research work, if done in Arabic, will be little, unfortunately. . . If you want to be widely recognized and popular in your discipline, you have to write and publish in English (4: 5-14).

You have to think about your readers before you publish. If you write in English you will certainly find more readers to read your papers than if you consider publishing in Arabic (9: 4-22).
Participants from the sciences also pointed to the increased difficulty of writing scientific papers in Arabic once they had commenced writing in English. It seems that when academics become accustomed to and familiar with English, it makes it difficult to change to writing in Arabic because the scientific terminology has not been developed to the same extent. In turn, to continue writing in English at the expense of Arabic means that authors are not in a position to contribute to the ongoing development and refinement of Arabic as a medium for science communication.

It is also uneasy to write in Arabic because of the scientific terminology that you get used to write in English but find it difficult to search for the counterparts in Arabic (2: 4-20).

The problem is that we get used to writing in English and our English has improved over time. We have not improved our writing in Arabic because of the English. But, if we are forced to write in Arabic, our Arabic will be improved (5: 7-3).

Frankly, I find it much easier for me to write a paper in English than writing it in Arabic (6: 4-22).

Some participants also pointed out that the lack of encouragement from governments and universities for the use of Arabic to enhance writing and publishing in Arabic may have an impact on the amount of Arabic information available in the networked environment. However, participants are aware that the current policies promote and reward the use of English for formal communication

The university also does not encourage 
writing research works in Arabic (4: 5-21).

Organizations and governments in the Arab World encourage publishing in English more than Arabic which affects negatively the impact of Arabic language on the academic environment and I think this is the most important factor that makes Arabic speaking academics publish in English (7: 6-9).

\section{The future of Arabic system of scholarly communication}

Interviewees were asked to anticipate and discuss the future of Arabic as a scholarly language in the networked environment. The responses of the interviewees were divided considerably between those who-despite the issues outlined abovestill retain some degree of optimism regarding the scholarly uses of Arabic, and those who were pessimistic about its future.

Those who were optimistic believe that with the advent of more advanced technologies, widespread digital literacy, enhanced ICT infrastructure, and increasing use of electronic publishing, that Arabic will inevitably come to be more widely represented on networks.

I am really optimistic about the roles that Arabic can play in the networked environment. I think it will be more available in the future, but we need to work hard (2: 5-7).

We will be progressing better in the networked environment. A lot of translation efforts will be made . . . I am optimistic about the influence of the Arabic language in the near future in the networked environment
(4: 5-26)

In my opinion, I think the future of Arabic in the networked environment is more determined now than ever before because Arabic has been technically supported in the Internet and it is easy to create and manage Arabic websites . . . Most people are becoming Internet literate and deal with the Internet on a daily basis. Methods of communication are now available and have become easier online (7: 6-21).

The future of the Arabic language in the scholarly communication will be better to some extent. . Globalization and domination of English will create a sense of responsibility towards our identity, It is a reverse reaction I think and that what will happen (12:5-14).

In contrast, the other group of participants anticipates a bleak outlook for Arabic in the networked environment because the domination of English will only become more apparent as networked information increasingly replaces printed material for both general and scholarly purposes. Moreover, Arab academics will be increasingly driven to write and publish in English, if not in the interests of their own careers, then as an inevitable consequence of globalization.

I am not optimistic about the future of Arabic as an academic language. People believe that one day English will become the language of the World and if you do not speak it, it will be hard to communicate internationally. There are some fears that so many other languages are going to be endangered because of English 
domination. It is part of the globalization (5: 7-77).

Unfortunately, I see the future of Arabic in the networked environment as dark in the near future especially if things remain still as they are now. Governments and universities overall do not support it and students in public schools are going to be taught scientific disciplines like math in English. Therefore, in this case the future does not look great (6: 5-3).

I think there would be not much difference than it is now. I tell you, it is difficult to communicate in Arabic . . , there is a fast growing trend to use and compete with English especially in the business sector (10: 6-6).

Nearly all participants to the interview indicated the importance of English for their research and scholarly communication. It was asserted that English is unavoidably the language of first choice for the purpose of scholarly communication. It has also been claimed by some interviewees that a lack of English proficiency is a major barrier to the productive use of networked information. English is also seen as the major driver of the transformation of scholarly communication in the Arab World, through its potential to communicate the contributions of Arab scholars to the rest of the world.

The interview results also show participants' belief that Arab universities are at a disadvantage when compared with their counterparts in more developed countries in relation to the effective use of ICTs. Among the problems identified were lack of training, lack of technical support and the absence of institutional encouragement. However, the results indicate that SQU is developing well in terms of supporting and enhancing the provision of networked information for academic purposes when compared to universities in other Arab countries.

In terms of increasing and enhancing the amount of Arabic networked information, the interviewees offered several suggestions that are likely to enhance the delivery of Arabic networked information at SQU and other Arabic academic institutions. In particular, they emphasized the importance of translation, and in this regard raised the prospect of collaboration with other academic institutions in the Arab World.

The results of the interviews supported the argument that the domination of English has substantially impacted on the attitudes of academics at SQU in conducting research and disseminating their findings. The results of the interviews further indicated the widespread preference for English over Arabic for the purpose of research and scholarly communication. All of the participants indicated that writing and publishing in English is more personally advantageous than writing and publishing in Arabic. The interviewees indicated a variety of factors that drive Arab academics to write and publish in English, pointing particularly to the difficulty of writing and publishing in Arabic in the science disciplines.

Despite these considerable challenges, some participants foresee the future of Arabic as a scholarly language as potentially brighter, due to the development of appropriate software that might transform the availability of Arabic in the networked environment. In contrast, other participants argue that Arab academics will be 
increasingly driven to write and publish in English, as it extends its reach and influence as the global language of choice for both scholarly and general uses.

Interviewees pointed to a number of reasons as to why English usage has become vital for Arab academics. Examples of these reasons include that English is: viewed as the international language of scholarship; easier to use for scholarly writing purposes than Arabic; the language used for the majority of scientific productivity; important for efficient use of technology, and; important for academic promotion.

\section{Discussion}

Although the Arabic literature reports no empirical studies that directly investigate the trend of language choice for the specific purpose of research and scholarly communication in the networked environment, there are several studies that report on the trend towards using English in preference to Arabic for both academic and public uses. Some of these studies discuss the technical requirements of Arabic as being a barrier toward developing and improving the presence of Arabic-based knowledge in the networked environment in general (Al-Khatib, 2000; Ali, 2003; Diab, 2003; Laroussi, 2003; Qasim, 2005), while other studies investigated the attitudes towards using the two languages in the Arabic educational environment (Al-Jurf, 2004; Findlow, 2006; Warschauer, El-Said, \& Zohry, 2002). Generally, these studies indicate that the trend towards using English in preference to Arabic is growing rapidly.

Several of these studies particularly refer to the issue of Arabic being under-represented on the Internet. For example, Ali (2003) argues that the current low-level of Arabic presence on the Internet does not accurately represent its importance as a language of scholarship, and Laroussi (2003) noted that Internet sites in languages other than Arabic are used much more than Arabic websites in various Arab countries. Qassim (2005) outlined the major factors that have negatively affected the use of Arabic in the networked environment. These factors include the concern of authors in achieving an international reputation and the need to make their research productivity more accessible and more widely recognized. In other words, it is the existing domination of English that further entrenches its position as the preferred language of international communication.

Other studies have reported the extent of the domination of English in some Arab universities and the impact this has on perceptions regarding the suitability of Arabic as a scholarly language. For example, Al-Jurf (2004) reported that the majority of the students ( $+80 \%$ ) from the University of Jordan and King Saud University, in responding to questionnaires, believed that Arabic is no longer suitable for teaching science disciplines. Nevertheless, the literature lacks empirical studies investigating the attitudes of academics towards their preference for using Arabic or English at a university level in Arab countries.

In addition to the technical problems associated with establishing Arabic as a language of high impact in the networked environment, there are many other difficulties that have negatively affected the use and spread of Arabic. While academics' attitudes in this regard have never previously been thoroughly investigated, part of the results of the current study indicate important factors that result in Arabic speaking academics being less likely to use Arabic for research and 
scholarly communication purposes in the networked environment.

In particular the English language preference demonstrated by Arab academics is mainly determined by the extensive international use of English for scholarly purposes. The results of this study suggest that the more that Arabic speaking academics adapt to writing and publishing in English, the less Arabic is considered to be an alternative language for research and scholarly communication. There is a confluence of global and local factors at play in this situation. On the one hand academics in Oman and other Arab countries are increasingly drawn into a network of communication that entices them to participate in international communities of scholars. In this environment English is the most widely used and influential language, to the extent that it threatens to dominate knowledge production throughout the world. As interviewees also noted, this international domination by English is given expression through local systems of incentive and reward. Important amongst these is the positive influence using English has for prospects of career advancement at SQU. In particular, several participants from science disciplines asserted that writing and publishing scholarly works in Arabic would negatively affect their chances for winning promotion at SQU.

The research literature includes no previous studies that have investigated this proposition in detail, but based on this perception indicated in this study, academics will clearly be discouraged from publishing in Arabic if English language alternatives are available. There is also evidence to suggest that perceptions linking the use of English to career prospects are generally held in the wider Arab World. A series of studies have reported the preferences of both Arab parents and students for learning in English because of its positive influence on career prospects (Al-Jurf, 2004; Findlow, 2006; Malallah, 2000).

Other problems seem to be systemic in that they reflect the lack of maturity of existing forums for scholarly communication in Arabic. As interviewees noted, Arabic speaking researchers are discouraged from publishing in Arabic due to the lack of suitable Arabic scholarly journals. Participants indicated that if Arabic scholarly journals do exist in their particular discipline, they often suffer from deficiencies in regard to quality, reputation, and international distribution when compared to similar journals published in English. Nasser \& Abouchedid (2001) have previously reported on this problem, noting that Arabic scholarly journals are comparatively very few and many have had a short lifespan. Those Arabic journals that do exist also tend to be 'general' in their nature and lacking the degree of specialization that characterizes English journals. Nasser \& Abouchedid (2001) indicated that Arabic journals have become the publishing choice of only untrained or early-career researchers. Nasser \& Abouchedid (2001) and Qasim (2005) have also asserted that although Arabic journals might exist in some disciplines, they suffer from the lack of efficient and systematic indexing, abstracting, and archiving services, and as a result academics and researchers are hesitant to use them as outlets for significant research publication.

The interview indicate that scholars from both disciplines of sciences, and humanities and social sciences, prefer to use English for communicating their research findings for a number of reasons including, but not exclusively, the difficulty of writing in Arabic in the science disciplines and 
also the lack of governmental and institutional support.

As a result of the above factors, it is to be expected that there will be an ongoing decline in the importance and recognition of Arabic as an effective scholarly language, especially for science disciplines. The currently held negative attitudes toward Arabic will hasten the decline of the language for scholarly uses, as researchers and their students seek to publish in English. As academics and researchers get increasingly familiar with reading and writing in English, it will become ever more difficult for them to write in Arabic. Not only are they likely to become less familiar with the scientific terminology used in Arabic, but that terminology itself may not develop at the rate required for current and accurate expression of scientific concepts. This will, in turn, negatively impact upon the use of Arabic as a language for scholarly exchange in the wider networked environment, as the future use of Arabic for networked communication is strongly tied to the capacity of the language to evolve as an effective vehicle for communicating the results of recent research.

Although the future of Arabic in the networked academic environment looks uncertain at best, it is significant that a number of interviewees in the current study remain optimistic in this regard. Almost half of the interviewees expressed some degree of optimism and even described a bright future for Arabic in the networked academic environment, in the Arab World at least. Those participants who expressed more negative attitudes, however, believe that English will maintain and increase its domination of scholarly communication, and as a result Arab academics will find it increasingly necessary to write and publish in English.

As reported above, there is a growing trend toward teaching and researching in English at many Arab universities and colleges, especially in the Arab Gulf countries (Al-Jurf, 2004; Al-Khatib, 2000; Findlow, 2006; United Nations Development Programme, 2003). Although Arabic has remained the language of teaching in some of the humanities and social sciences disciplines, almost all science disciplines including applied sciences, engineering, medicine, commerce and agriculture are now being taught exclusively in English. As indicated earlier, teaching sciences in English is strongly associated with acquiring the requisite information, knowledge and skills, and Arab academics-especially in science disciplines-are progressively and increasingly driven and motivated to conduct and publish research by means of English or other non-Arabic languages.

While the Internetand advanced ICTs have brought new challenges for Arabic as an academic language (United Nations Development Programme, 2003), and while Arabic has not responded quickly and adequately to meeting these challenges, Arab universities have found it easier to adapt to English as a readily available and effective substitute. Laroussi (2003) indicates that once users' needs for information are met by languages other than Arabic, users do not make further efforts to ascertain whether this information is also available in Arabic. Therefore, while Arabic speaking academics or individuals find themselves not being sufficiently and technically well supported to use Arabic networked information, English and other languages based on Latin alphabets are increasingly both more accessible and more comfortable to use. The 
results of the current study, however, strongly support the conclusion that the use of networked information in English in Arab countries is being driven by a lack of scholarly Arabic literature on the networked environment.

While it is expected that the Arab academic institutions should be at the center of research aimed at enhancing the provision and use of Arabic networked information, any advances in this regard will only be achieved by the availability of adequate funding. Indications are, however, that a lack of funding has negatively impacted on the productivity of research-based publication in the Arab World (United Nations Development Programme, 2003). Moreover, a lack of governmental and local support in publishing networked scholarly works in Arabic is apparent in many Arab countries. Lack of financial resources and lack of governmental and institutional encouragement and support to enhance the level of Arabic information on networks have resulted in "research projects [that] often lack clear objectives, [lack] a firm results orientation and a sense of urgency linked to producing high-impact developmental outcomes within a time-bound plan" (United Nations Development Programme, 2003, p.74).

Although there is no straightforward explanation as to why Arab universities do not make greater efforts to encourage and support the publishing of scholarly works in Arabic, it is apparent that Arab governments and academic institutions perceive that they benefit more from publishing their research outcomes in English rather than Arabic because publishing in English allows a wider distribution of their contributions to knowledge production and human development. Despite the mounting awareness of a crisis in the scholarly use of Arabic (Qasim, 2005; United Nations Development Programme, 2003), governmental or institutional efforts or responses to address the situation have not been forthcoming. Therefore, Arabic has continued to suffer from the challenges associated with the rise of ICT, and particularly due to the lack of a unified linguistic policy or professional and financial support at regional, national, or institutional levels.

Again, the results of the interviews strongly indicate a considerable deficiency in efforts by Arab academic institutions to enhance the use of networked information, and particularly the use of networked information in Arabic. Similar to related research outcomes (Diab, 2003; Laroussi, 2003; Qasim, 2005), the shift toward using foreign languages in the Arabic academic environments can be seen as the result of a lack of important infrastructure (both software and hardware), insufficient translation facilities, the absence of regional collaboration, and a shortage of adequate financial support. The gap between developed and developing countries still exists in terms of facilitating access to ICTs. While there are still Arab universities that have not yet been sufficiently equipped and facilitated with advanced ICTs (Abdulaziz, 2005), there are indications from the interviews in the current study, that even in those Arab academic institutions which are sufficiently equipped and provided with adequate access to networked information, the academics might not take full advantage of such services because of the lack of relevant training, or their own reluctance to adapt.

While there have been many claims made in the Arab World regarding the importance 
of translation services in boosting the use of information in Arabic, and the success of other countries-for example Japan-in increasing research and business productivity based on efficient translation, this solution has not received the close attention of governments that would seem to be warranted. According to the United Nations Development Report, translation in the Arab World is at alarmingly low levels. For example, the total amount of text translated in all Arab countries for a 5-year period was less than $0.5 \%$ of that which was translated in Spain in the same period (United Nations Development Programme, 2003). Participants in this current study vigorously support and encourage the idea of paying increased attention to translation as a key driver for improvements in research in Arab universities.

Scholarly journals have long been established as the key vehicle for the transfer of scholarly information. In recent years the developed countries have led the reinvention of the process of formal scholarly communication based on electronic availability of scholarly journals (e-journals), as a result of which most major international journals in English are now available in this format. This provides these journals with the significant advantage of being accessible anytime and (almost) anywhere.

As indicated in the previous discussion of the results of this study, the current system of scholarly communication at SQU is heavily influenced by the academics' increasing concern for, and use of, the English language. The results of this study indicate that language is a determinant factor which influences the future of scholarly communication in the Arabic academic environment, especially when language is considered to be the most distinctive and essential trait of any society (United Nations Development Programme, 2003).

Arab countries, however, are not more idiosyncratic on their extensive adoption of English for scholarly communication than other regions like Western Europe or East and Southeast Asia. The literature indicates a growing trend to the use of English as a scholarly language in countries like Netherlands, Italy, Germany, France, Spain, and Russia (Trady, 2004 \& Research Trends, 2008). Empirical evidence of growing trends toward the use of English for research and scholarly communication has also been reported, for example, in China, Japan, Korea, Singapore, Malaysia, and India (Xia, 2008). But, there is no evidence on whether English has imposed a reversing impact on the local systems of scholarly communication in these countries.

The results of this study strongly suggest that English will increasingly be used for research and scholarly communication purposes at SQU, and that this is likely to be the case for similar Arab academic environments. The system of scholarly communication in Oman and other Arab countries is likely to develop slowly, however, unless strenuous efforts are made to implement and maintain a robust system of scholarly communication based upon the culture and language of the Arabic societies. The question must be asked whether any society can be said to have a healthy research environment, capable of invigorating relevant debate and public policy, if it depends upon a system of scholarship that employs a language for research and communication that is foreign to the population it serves. 
Currently Arab governments and universities are addressing the desire for increased international research presence and credibility by embracing the use of English. This may prove to be expedient in the short term, and indeed in the long term for some disciplines, but it may result in a permanently impoverished research environment and culture for those disciplines to which the use of Arabic remains intrinsic.

This is not a problem peculiar to SQU or Oman, and it is likely that it can only be addressed by collaborative action across a number of Arab nations. This may involve long term action, such as cooperation in developing and promoting the use of a standardized form of academic Arabic which is adapted to both the demands of scholarly interchange and the requirements of the ICT environment on which it will depend. Diab (2003) indicates that delays in standardizing Arabic will lead to an increased failure in the communication system within the Arab countries; a fragmentation of the information and communication technology marketplace in these countries, and reduced technological representation of the Arabic language. Laroussi (2003) notes that, as yet, there have not been any unified agreements, strategies, or visions to support Arabic with technologies that are suited to its presentation in the networked environment.

A regional collaborative and strategic plan to boost the system of scholarly communication with particular emphasis on increasing the level of Arabic available in networked environments is necessary in order to bring positive benefits to the current system of scholarly communication as experienced in Oman. In light of the results of this current study, and based on the interviewees' responses, it does not appear that such an outcome is likely in the short term.

\section{Conclusion}

The results of the research indicates that English has been widely used for the purposes of teaching and research at SQU, particularly in the science disciplines where English is mandated as the teaching language and, subsequently, the language used for research. The study has provided evidence of the detrimental impact the international domination of English for scholarly communication has had on the use of Arabic for scholarly purposes. The domination of English as a global scholarly language has been replicated in the networked environment where it is widely used for both scholarly and general uses. This has severely hampered the potential for Arabic to establish a similar networked presence.

The study indicates that academics' use of networked information for research and scholarly communication at SQU has been substantially influenced by linguistic issues. Many academic institutions in the Arab region have recently extended the use of English language for both teaching and research purposes. The research reported in this study indicates that this has resulted in a period of uncertainty for some researchers, who are unsure of the extent of the threat to the types of knowledge that have traditionally been imparted in Arabic. The advent of ICTs, particularly the Internet and related networked information sources, have bifurcated the system of Arab scholarly communication in a way that threatens to produce separate spheres of knowledge.

The interview results indicate, however, that while understanding the threat English poses to Arabic, many participants also value the use of English 
for scholarly purposes. They understand that they function in an academic environment that privileges and rewards the use of English. They are therefore acutely conscious of the pre-eminent position enjoyed by English, and the importance this has for enhancing the learning of their students, and their prospects for internationalizing their research outcomes. They also stressed that the use of English is important for the efficient use of computers and Internet technologies.

It is therefore not surprising that the study reveals a substantial ambivalence regarding the use of English and its impact on Arab scholarship. On the one hand it is seen as an important element in the development of the Arab higher education sector, but on the other hand it threatens established traditions of scholarship that are integral to Arab societies.

It should be acknowledged that these attitudes have been shaped by a policy environment that is characterized by a lack of institutional or governmental support for the continued use of Arabic for educational purposes, and the absence of associated strategic planning or cooperation in the Arab World. For example, while the surge of availability of English language e-journals has radically altered the availability of scholarly communication in the developed world, there has been no corresponding implementation of Arabic e-journals, particularly in science disciplines. As a result, the domination of English is further entrenched. 


\section{References}

Abdulaziz, T. O. 2005. Benefits of the Internet for Egyptians Academics in Social Sciences Disciplines. Majallat Maktabat Almalik Fahad Alwataniyya (Journal of King Fahad National Library), 1 1(1), 179-222. (Source in Arabic).

Ali, N. 2003. The Challenges of the Information Era. Cairo: Maktabat Alausra (Source in Arabic).

Al-Jurf, R. S. a. 2004. Youth Attitudes Toward Using English or Arabic Languages in Education. Diwan AlArab, March. (Source in Arabic).

Al-Khatib, M. A. 2000. The Arab World: Language and Cultural Issues. Language, Culture, and Curriculum, $13(2), 121-125$.

Diab, H. (2003). Standardization Related to Arabic Language Use in ICT. Paper Presented at the Western Asia Preparatory Conference for the World Summit on the Information Society (WSIS), Beirut, 4-6 February 2003.

Findlow, S. 2006. Higher Education and Linguistic Dualism in the Arab Gulf. British Journal of Sociology of Education, 27(1), 19-36.

Kebede, G. 2002. The Changing Information Needs of Users in Electronic Information Environment. The Electronic Library, 20(1), 14-21.

Laroussi, F. 2003. Arabic and the New Technologies. In J. Maurais \& M. A. Morris (Eds.), Languages in a Globalising World (pp. 250-259). Cambridge: Cambridge University Press.

Malallah, S. 2000. English in an Arabic Environment: Current Attitudes to English among Kuwait University Students. International Journal of Bilingual Education and Bilingualism, 3(1), 19-43.

Nasser, R., \& Abouchedid, K. 2001. Problems and the Epistemology of Electronic Publishing in the Arab World: The Case of Lebanon. First Monday, 6(9).

Qasim, H. 2005. Scholarly Communication in the Electronic Environment. Cairo: Dar Gharib. (Source in Arabic).

Research Tends. 2008. English as the international language of Science. Research Trends, 6, 1-9.

SQU. 2006. Sultan Qaboos University. Retrieved September 6, 2010, from http://www.squ.edu.om

Tam, L. W. H., \& Robertson, A. C. 2002. Managing Change: Libraries and Information Services in the Digital Age. Library Management, 23(9), 369-377.

Trady, C. 2004. The role of English in scientific communication: Lingua Franca or Tyrannosaurus rex?. Journal of English for Academic Purposes, 3(3), 247-269

United Nations Development Programme. 2003. Arab Human Development Report 2003: Building a Knowledge Society. Retrieved November 1 1, 2010, from http://www.undp.org.sa/Reports/AHDR\%20 2003\%20-\%20English.pdf

Wang, Y.-M., \& Cohen, A. 2000. Communicating and Sharing in Cyberspace: University Faculty Use of Internet Resources. International Journal of Educational Telecommunications, 6(4), 303-315.

Warschauer, M., El-Said, G. R., \& Zohry, A. 2002. Language Choice Online: Globalization and Identity in Egypt. Journal of Computer Mediated Communication, 4(July).

Xia, J. 2006. Scholarly Communication in East and Southeast Asia: Traditions and Challenges. IFLA Journal, 32(2), 104-112. 